\title{
Candidiasis: Predisposing Factors, Prevention, Diagnosis and Alternative Treatment
}

\author{
Natália Martins • Isabel C. F. R. Ferreira • \\ Lillian Barros • Sónia Silva $\cdot$ Mariana Henriques
}

Received: 3 January 2014/ Accepted: 18 April 2014/Published online: 1 May 2014

(C) Springer Science+Business Media Dordrecht 2014

\begin{abstract}
Candidiasis is the most common opportunistic yeast infection. Candida species and other microorganisms are involved in this complicated fungal infection, but Candida albicans continues to be the most prevalent. In the past two decades, it has been observed an abnormal overgrowth in the gastrointestinal, urinary and respiratory tracts, not only in immunocompromised patients, but also related to nosocomial infections and even in healthy individuals. There is a widely variety of causal factors that contribute to yeast infection which means that candidiasis is a good example of a multifactorial syndrome. Due to rapid increase in the incidence in these infections, this is the subject of numerous studies. Recently, the focus of attention is the treatment and, above all, the prevention of those complications. The diagnosis of candidiasis could become quite complicated. Prevention is the most effective "treatment," much more than eradication of the yeast with antifungal agents. There are several aspects to consider in
\end{abstract}

N. Martins · I. C. F. R. Ferreira ( $₫)$ L. Barros Mountain Research Centre (CIMO), ESA, Polytechnic Institute of Bragança, Campus de Santa Apolónia, Apartado 1172, 5301-855 Bragança, Portugal e-mail: iferreira@ipb.pt

N. Martins $\cdot$ S. Silva $\cdot$ M. Henriques $(\bowtie)$ IBB - Institute for Biotechnology and Bioengineering, Centre of Biological Engineering, University of Minho, 4710-057 Braga, Portugal

e-mail: soniasilva@deb.uminho.pt the daily routine that can provide a strength protection. However, a therapeutic approach is necessary when the infection is established, and therefore, other alternatives should be explored. This review provides an overview on predisposition factors, prevention and diagnosis of candidiasis, highlighting alternative approaches for candidiasis treatment.

Keywords Candidiasis · Predisposing factors · Diagnosis · Prevention - Alternative treatment . Therapeutic approach

\section{Introduction}

Candida species are involved in the main opportunistic yeast infection in the world, candidiasis, but among the species of the genus, Candida albicans continues to be the most common. Although this yeast is responsible for approximately 50-90\% of human candidiasis, C. albicans is part of the commensal flora of more than half of the healthy population. Colonization by this yeast is beneficial to the host, because not only limits the growth of other opportunistic pathogenic fungi, but also promotes the functioning of the immune system [1-5].

In the last two decades, it has been observed a considerable increase in the incidence of deep fungal infections, not only in immunocompromised patients, 
but also related to nosocomial infections, and even in healthy population [4, 6-15]. Thus, with the increased incidence of deep fungal infections (chronic candidiasis), the primitive idea that they were related to a restrict number of pathogenic fungi and specific geographical area was completely changed. Furthermore, with the rapid increase in candidiasis incidence, other Candida species and microorganisms besides $C$. albicans have been involved in such infections [2, 5, 6, 16-18]. The balance between C. albicans and nonCandida albicans Candida (NCAC) species determines the profiles associated with virulence. So, the most common species are $C$. albicans, $C$. tropicalis, $C$. glabrata, C. dubliniensis, C. parapsilosis, C. orthopsilosis, C. metapsilosis, C. krusei, C. famata, C. guilliermondii and $C$. lusitaniae. Other relevant fact associated with virulence is their capacity to form biofilms with other species, which together with the presence of teleomorph forms (sexual phase of fungi in which the same biologic entity could have two different scientific names), difficult the treatment and alter the susceptibility profiles to traditional antifungal agents [3, 9, 10, 13, 19-22].

Although biofilm formation lead to an increase in the persistence and resistance to antifungals, other factors, such as adaptation to the $\mathrm{pH}$ level, adherence of yeast cells to the host cells, proteolytic enzymes, phenotypic switching and morphological transition (ability of yeast to change morphologically from blastoconidia to pseudohyphae and hyphae), affect the strategies to prevent and treat this pathogenic infection. Despite C. albicans is still the focus of a wide range of studies, some researches have been demonstrated a significant increasing of infections caused by NCAC species. There are some associated factors with the virulence. The presence of hemolytic exoenzymes is very important because it allows an acquisition of iron ions from hemoglobin, by yeasts. Moreover, there is a positive correlation between this metal and the establishment and dissemination of infections. The metabolic activity and the capacity of biofilm formation also appear like important correlating factors of pathogenicity, once they interfere in the level of virulence expression and in the level of resistance to antifungal agents. A high metabolic activity of NCAC species was demonstrated, which could be a cause of the increasing frequency of fungal infections related to these yeasts, including the possibility of systemic infections. According to these facts, it was possible to demonstrate the complexity of the epidemiological chain of colonization-infection processes. Like expression of virulence-associated factors is strain dependent, an accurate identification of yeasts and their virulenceassociated factors is essential to detect the emergence of yeasts and to predict the antifungal agents response, considering the increasing tolerance and antifungal resistance mechanisms [1, 2, 20, 22-24].

Due to the increasing evidence of antimicrobials and antifungals resistance, several studies have been developed toward the identification and evaluation of efficient alternative therapeutics. Natural products, in particular, those from plants, have been explored with that purpose; the therapeutic potential of phytochemicals, the synergistic effects among them and the related mechanisms of action have been extensively studied [25-35]. Nevertheless, many extracts/compounds from plant origin remain unknown and could constitute an alternative or complementary treatment for candidiasis.

Considering all the stated candidiasis is indeed much more than $C$. albicans overgrowth, and therefore, the most relevant topics involved in this fungal infection are presented and discussed in the present manuscript, namely description of candidiasis and their main classes, predisposing factors, diagnosis (signals, symptoms and methods), prevention and alternative treatment (diet and nutrition, enhancing immunity system, detoxification, natural antiyeast agents and therapeutical approach) (Fig. 1).

\section{Description of Candidiasis and Main Classes}

Yeasts are part of the commensal fungi flora of the healthy population. However, with the significant and rapid increase in the incidence of opportunistic fungal infections, the focus of attention has been the treatment and, above all, prevention of those complications. Although other fungi species are involved in nosocomial infections, such as Aspergillus spp., Zygomyces spp., Fusarium spp., Scedosporium spp., Cryptococcus spp., Trichosporon spp., Geotrichum spp. and Rhodotorula spp., C. albicans continues to be the most prevalent, counting to $50-90 \%$ of the isolates from fungal infections [1, 9, 10, 22, 36, 37].

Candida albicans is a common species in genitourinary and gastrointestinal tracts of healthy people, but it is also able to cause problems, mainly vaginal 


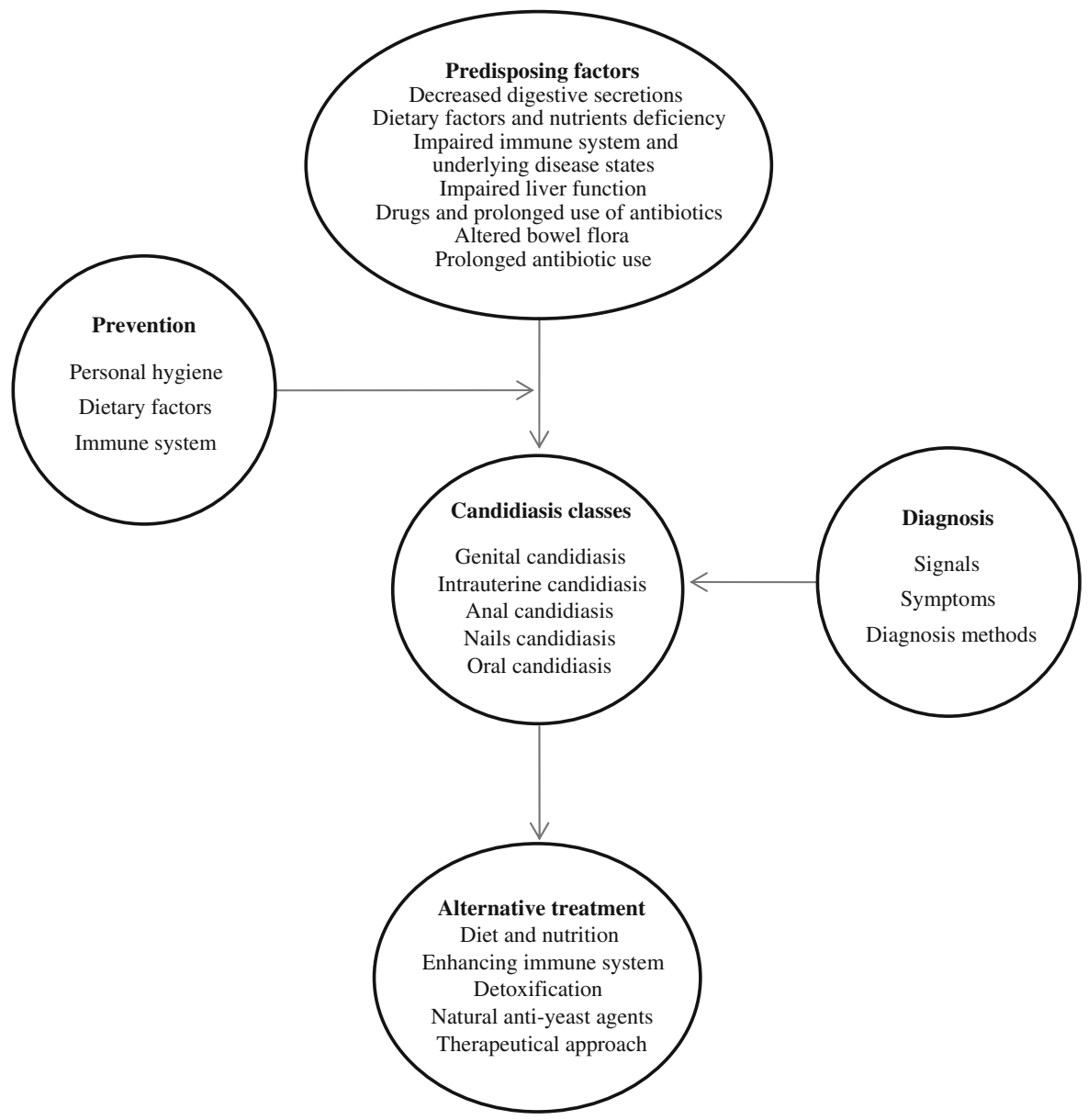

Fig. 1 Representative scheme of interactions between the main variables related to candidiasis

infections in woman. This microorganism is responsible for mouth and mucocutaneous infections. However, it has been frequently observed an evolution to chronic forms, generating complicated infections, such as septicemia, endocarditis, meningitis and peritonitis, especially in patients with reduced immune function or taking antibiotic therapies. Some reports described that oral candidiasis appeared as early as the second century A.D. by Galen, who described it as aphthas albus. Other reviews reported that it was not until the mid-nineteenth century that clinical nature of oral candidiasis was defined and the etiologic agent identified. Notwithstanding, and despite the other types of mucocutaneous candidiasis, oral candidiasis is still the most frequent. There has been a wide variety of synonyms used for the members of genus Candida, 166 synonyms being recognized for $C$. albicans worldwide. Actually, there are between 150 and 200 species recognized in the genus, but only seven Candida species are classified as having major medical importance, being $C$. albicans the most important one. Other Candida species such as $C$. tropicalis, $C$. glabrata, C. parapsilosis, C. stellatoidea, C. krusei and $C$. kyfer are encountered in human infections [2, 5 , 15, 38, 39].

The increase in the number of organ transplantations, the rise of immunocompromised individuals and the use of invasive devices (catheters, artificial joints and valves) are a major factor that contributes to higher patient's susceptibility to nosocomial infections. Despite being Candida species the fourth leading cause of hematogenous infections, these species are not exclusively related to nosocomial infections (candidemia), because the same infections can also occur in healthy population. There are several classes of candidiasis, which have become more 
common in recent years $[4,6,13,17,40,41]$. Depending on body location, the mucocutaneous candidiasis can be classified as genital candidiasis, intrauterine candidiasis, anal candidiasis, nails candidiasis and oral candidiasis (Fig. 1).

\section{Genital Candidiasis}

Vulvovaginal candidiasis (VVC) is the most frequent type of genital yeast infection. Approximately $75 \%$ of women experience, at least once in their lifetime, an episode of VVC, 40-50\% experience at least one additional episode of infection, 20-50\% remain without any clinical manifestation and lastly, $5 \%$ experience recurrent VVC episodes [9, 10, 42, 43]. Although, not being a threat to life, it is unpleasant and problematic, causing a variable degree of itching and whitish discharge, abundant and flocculent. This infection is very common in pregnant women, especially in the last trimester of pregnancy, when a variation in progesterone, estradiol and glycogen, associated with an increase in vaginal $\mathrm{pH}$, favors the emergence of these infections. In this case, special attention should be given due to the potential occurrence of contamination of the fetus in the uterus, or even the child during childbirth. On the other hand, it has been observed that, in individuals with diabetes, the incidence of vaginal candidiasis is higher. Similarly, patients submitted to broad spectrum of antibiotic therapy, used to treat bacterial infections, and even the use of oral contraceptives, are also important factors associated with higher rates of incidence of VVC [42, 44-47].

In men, balanitis, which usually appear after sexual contact, is characterized by the appearance of a rash, more or less prickly, followed by small pustules on rocking groove-preputial discharge, more or less abundant. Although this kind of injury is well defined, in particular cases it can extend to the groin and perianal region. The major factors associated with this type of infections are antibiotic therapies, diabetes and vaginal secretions of the sexual partner $[1,17,48]$.

\section{Intrauterine Candidiasis}

This type of infection is frequent during pregnancy. It is important to avoid the occurrence of this type of intense vaginitis in the last few weeks of pregnancy, because it can complicate and extend to the uterus, infecting the child before birth. At childbirth, or in the first hours of life, it can be observed a widespread rash, maculopapular or pustular-vesicular. During the following weeks after birth, the clinical status may be complicated, extending to other body locations, which usually are treated with local antibiotics [5, 42, 43, 49].

\section{Anal Candidiasis}

This type of infection is characterized by intense itching/pruritus, accompanied by burning sensation, and localized erythema around the anus. Skin may appear macerated with circumscribed lesions, which may eventually invade the intergluteal groove [49-51]. This type of infection is most common in children, despite the frequency in women due to the use of hormonal contraceptives, intimate hygiene products, clothing and their practice of oral and anal intercourse, functioning as transient colonization of local organisms shed from the intestinal tract. As candidiasis can be sexually acquired, males can be affected, because they may acquire infection from the gastrointestinal tract of their partners. However, in some cases, the factors causing that condition are still unknown, but seems that the main problem of this pathogenesis are secondary infections caused by aerobic and facultative anaerobes microorganisms, such as Staphylococcus spp., Streptococcus spp. and Escherichia coli [48, 50-52].

\section{Nails Candidiasis}

Candida species are not considered normal yeasts on nails flora. Therefore, this type of infection is a sign of colonization (secondary growth) despite primary infections of nail fold and nail bed with Candida species may also occur, which are related to a disease of the nails. Onychodystrophy or periungual tissue is related to nail disease. This type of infection may appear, such as paronychia and onychia. The paronychia is characterized by an inflammation, more or less painful, in peripheral skin nail, which appears red and brilliant. The predisposing factors are essentially, sex, different traumas (e.g., in manicure), professional activity and hormonal variations. Although infrequent in males, this infection can appear in cooks, confectioners and employees of canning factories [1, 17, 49].

Usually, the nail injury itself, or onyxis (ingrown nail), is secondary to paronychia. It is characterized by a progressive striation, dyschromias (discoloration) 
and opacity of the nail plate, which ultimately becomes crumbly. This infection appears abruptly and painfully, leading to detachment of the nail and can spread to other nails. Still, it can be observed fungal colonization in interdigital areas, by Candida species, commonly known as digital intertriginous. Preferentially, it is located in the hands and between the ring and middle fingers, although it can also appear in the corners of the fingers. It is commonly associated with professions or occupations in which there is a frequent contact with water. The injury erythemascaly, itchy and exudative generally is well delimited peripherally, and the epidermis appears detached. It is less frequent in feet, but can reach one or more commissures of fingers $[1,17,49,50]$.

Intertriginous can still be located at the level of the submammary, mainly in obese women, suprapubic fold, groin and intergluteal cleft. It is characterized by the appearance of small vesicles and pustules, which, by breakage, give rise to exudative red spots [1].

\section{Oral Candidiasis}

Oral and perioral candidiasis is the more common type of acute mucocutaneous candidiasis. It is characterized by the appearance of small spots or whitish papules on the tongue, inside the cheeks and in the palate, forming a creamy and very adherent layer mucosa. In some cases, it may extend up and cover the tongue, palate and pharynx, but also corners of the mouth could be reached. When this happens, it is labeled as angular cheilitis, being evidently a mucosal thickening and cracking. This type of candidiasis particularly affects people with immune system disorders and people with dental prostheses. It can be also found in patients receiving chemotherapy for cancer treatment, or taking immunosuppressive drugs to protect transplanted organs or in patients infected by HIV. In children and young people, it may be involved with oral ("thrush") and lingual disease. In addition, and despite being very rare, esophageal candidiasis can occur in patients infected by HIV and cancer [2, 5, 40, 53-55].

\section{Predisposing Factors}

Although Candida species is commensal to human organism and virtually present in healthy people, in the past two decades, an abnormal overgrowth in the gastrointestinal (GI), urinary and respiratory tracts has been observed [2, 3, 6, 10, 56]. During some days after childbirth, that species colonize the mucosa of GI tract (40-50\%) and upper respiratory passages, as well as the mouth, pharynx and larynx. Normally, C. albicans lives smoothly in the inner warm creases and crevices of the GI tract (and vaginal tract in women). During pregnancy, Candida species colonization increases 30-40\%, depending upon altered immune response, bacterial flora, positive variations in glycogen and $\mathrm{pH}$ levels; however, mostly during the normal life cycle, other factors can affect, such as hygiene and oral contraceptive use, which contributes to $5-30 \%$ of the infections. In men, up to $10 \%$ of these species are found on the genitalia, in the transitional zone, between the mucous membrane and the skin $[1,13,18,40,44$, 46]. The overgrowth of $C$. albicans is an important cause of a wide variety of symptoms that affect directly the well-being of individuals, and therefore, there is an urgent need to recognize candidiasis as a complex medical syndrome and evaluate the magnitude of the problem regarding prevention, which passes through the control of risk factors.

There are several factors that contribute to yeast infection, which means that candidiasis, and more especially chronic candidiasis, is a good example of a multifactorial syndrome. In the next steps, the major and most important factors are explained, namely decreased digestive secretions, dietary factors, nutrients deficiency, impaired immune system and underlying disease states, impaired liver function, drugs and prolonged use of antibiotics and altered bowel flora (Fig. 1).

\section{Decreased Digestive Secretions}

In a normal organism, the digestive secretions, such as hydrochloric acid, bile and pancreatic enzymes, have an important role not only for a correct digestion, but also to prevent Candida overgrowth and its penetration into absorptive surfaces in the GI tract. Therefore, an improvement in digestive secretions is pivotal and, in some cases, is an important step to treat chronic candidiasis.

Pancreatic enzymes perform an important role as therapeutic agents enabling an efficient and complete digestion of proteins and other dietary compounds. Any dysfunction on this process leads to several problems, such as food allergies and formation of toxic substances. Furthermore, those enzymes are 
responsible for the preservation of the integrity of small intestine without parasites and other opportunist microorganisms (bacteria, yeasts, worms and protozoa), helping in the degradation of immunocomplexes [57, 58].

The intake of antacids and antiulcer drugs has a high risk of GI infections, showing a Candida species overgrowth in the stomach. Therefore, to restore the normal digestive secretions to proper levels, through the use of supplementary hydrochloric acid, pancreatic enzymes and substances that promote the normal bile flow is highly important in the treatment of chronic candidiasis $[57,58]$.

Dietary Factors and Nutrients Deficiency

A balanced organism needs all the macro- and micronutrients in right proportions, and therefore, any unbalanced diet affects the well-being of the body and potentiates growing and colonization of certain invaders. Some foods, such as refined sugars, sucrose, fruit juice, honey and maple syrup, have an important interference, functioning like growth enhancers. Moreover, foods with high content of yeast and fungi favor the growth of Candida; some examples are cheeses, alcoholic beverages and dried fruits. Another food group that stimulates growth is milk and dairy products, not only because of the high content of lactose but also, in some cases, due to the presence of antibiotics. Another important situation observed in most individuals with chronic candidiasis is the presence of food allergies, and therefore, all known allergens should be eliminated [40, 42 , 55, 57, 59-61]. Thus, dietary factors should be monitored according to the needs of each individual.

Some essential nutrients usually in deficit on chronic candidiasis are zinc, magnesium, selenium, essential fatty acids, folic acid and vitamins B6 and A [57, 59, 60, 62]. Furthermore, iron has been considered as an essential micronutrient rather than a supplement, and there are several recent studies that indicate its important role in fostering and colonization by microorganisms, including Candida and other yeasts $[9,42,63-66]$.

Impaired Immune System and Underlying Disease States

Dysfunctions of the immune system turn the human body more vulnerable to various kinds of infections.
Thus, it is of extreme importance to maintain the good conditions of the immune system in order to prevent overgrowth of certain microorganisms and opportunistic infections. By itself, a weak immune system is already sufficient to constrain the health and resistance of individuals, although with the current and prolonged/ frequent consumption of antibiotics, chemotherapy, steroids, radiation, stress, as well as some environmental contaminants, the body is still more susceptible. Furthermore, any disease that, directly or indirectly, affects the immune system increases the body's susceptibility to the growth and development of pathogenic and opportunistic microorganisms. This is the case of some increasing prevalence diseases, such as cancer, diabetes and hypothyroidism, that in addition to debilitate immune system of individuals has led to a continuous and exacerbated prescription of immunosuppressant drugs $[1,11,17,18,24,37,40,41,67-69]$.

In fact, the most common diseases that predispose to an increased sensitivity to $C$. albicans overgrowth are diabetes mellitus, cancer, leukemia, AIDS, thyroid dysfunction and other diseases, in which host defense mechanisms are suppressed or adrenal cortex steroids/ antibiotics/other similar drugs are used (immunosuppressed patients) $[6,10,12,24,25,37,40,53,56,70-72]$.

\section{Impaired Liver Function}

The modifications of the liver functions, as a result of injury or chemical causes, can change detoxification mechanisms. In this situation, as the liver is not able to perform its functions properly, toxins are absorbed by the intestine being accumulated, which affects more the liver and other organs function, and increase the body's sensitivity to chemicals. The accumulation of toxins in the body, as a result of liver damage, associated with changes in the mechanisms of detoxification, also stimulates $C$. albicans overgrowth. One way to diagnose if liver function is affected or if the mechanism of filtration of the blood is not properly being done is through the manifestation of symptoms (e.g., psoriasis, premenstrual syndrome, among others) of chronic candidiasis outside of digestive tract $[57,60,73,74]$.

Drugs and Prolonged Use of Antibiotics

Antibiotics have been identified as a major responsible factor for the development of chronic candidiasis. 
Since its mode of action is based on the elimination of intestinal bacteria, responsible for preventing the growth of yeasts and other pathogenic organisms, as well as suppressing the immune system, antibiotics action result in a $C$. albicans overgrowth. This situation becomes shortly a vicious cycle: A person with an alteration of the immune system is more susceptible to infections, and consequently, more infections will appear-increasing the doses and frequency in the consumption of antibiotics. This fact not only favors the overgrowth of $C$. albicans and other yeasts, but particularly bacteria, which increasingly develop mechanisms of resistance against antibiotics [6, 17, 42, 57, 69].

An established fact is that the indiscriminate use of antibiotics substantially increases the risk of developing complications caused by $C$. albicans and other resistant pathogens. This is particularly important in hospitals because nosocomial infections by resistant microorganisms often lead to lethal complications. Therefore, the reduction in the prescription and use of antibiotics can be considered an effective alternative to control and/or minimize the resistance problem. Another alarming factor is the widespread use of antibiotics in animals, which not only contribute to microbial resistance in animals themselves, but also indirectly affect humans: antibiotic resistance and consumption of food contaminated by antibiotics $[1,6,17,23,40,42,43,46,70$, $75,76]$. The increasing incidence of Crohn's disease and other inflammatory bowel diseases, which previously were only prevalent in populations with a strong genetic component, is also an important factor [77-86].

Other drugs that could favor C. albicans overgrowth are corticosteroids, oral contraceptives and antiulcer drugs. It should be emphasized that individuals who take antiulcer drugs, such as ranitidine and cimetidine, may develop $C$. albicans in the stomach $[6,7,40,42,43,46]$.

\section{Altered Bowel Flora}

As described, drugs and other chemical compounds greatly affect the well-being of the body. If the liver does not work properly, products and metabolites resulting from poor digestion are accumulated in the body causing toxicity and, at the same time, favoring pathogenic strains, and also C. albicans overgrowth.
Therefore, intestinal flora is of utmost importance in maintaining proper intestinal health and balance, being involved in the maintenance of nutritional status, immune system function, cholesterol metabolism, carcinogenic agents and aging. It is imperative to promote healthy and growth of beneficial intestinal flora, not only after taking antibiotics, but also in other situations. It should also be noted that chronic stress greatly affects the balance of intestinal flora and suppresses the immune system function. In other hand, especially in women, the hormonal balance is very important and the oral routine of contraceptive use is itself a predisposing factor to $C$. albicans overgrowth once it is a causative agent of variation in the balance of the intestinal microflora $[1,6,9,23$, $40,42,46,87,88]$.

\section{Diagnosis}

In some cases, the diagnosis of candidiasis becomes quite complicated and difficult to establish, since the patients present different signals and symptoms according to age, gender, host resistance and exposure to environmental factors. Nevertheless, some tools could be used to screen and determine the presence of yeast infections (diagnosis), namely questionnaire, comprehensive digestive stool analysis (CDSA) and laboratorial techniques (Fig. 1).

\section{Signals and Symptoms}

Despite fungi and other microbials being widespread in the environment, the systemic infections thrive very slowly. Most of the times, the individual infected does not have symptoms or visible signals. According to some authors, namely oral candidiasis is classified considering the following aspects: duration (acute or chronic), clinical features, like color (erythematous/atrophic), location (median rhomboid glossitis, denture stomatitis, multifocal candidiasis and angular cheilitis), presence of skin lesions, as well as oral lesions (mucocutaneous) and association with an immunocompromised host (HIV associated). Other clinical aspects included hyperplastic or hypertrophic appearance, characterized by papillary hyperplasia of the palate, candida leukoplakia and hyperplastic median rhomboid glossitis $[1,5,17,48$, $49,57,59,60]$. 
In a more developed stage of infection, a simple sensation of flu or constipation could occur, such as cough or fever, chest pain, chills, weight loss or breathing difficulties. However, the type and the intensity of signals and symptoms depend on the type and location of the infection. One of the major explanations for yeasts overgrowth is that the immune system mechanisms are depleted, or the normal lining of the intestinal tract is damaged. When this happens, the body can absorb yeast cells, particles of yeast cells, a wide of toxins and other substances, resulting in the development of yeast syndrome [5, 49, 62].

The major symptoms of patients with yeast infection are divided in different categories, which are described below. General symptoms include chronic fatigue, loss of energy, general malaise and decreased libido. Other category includes gastrointestinal symptoms, such as thrush, bloating, gas, intestinal cramps, rectal itching and altered bowel function. In genitourinary system, the major complaints are vaginal yeast infection and frequent bladder infections. Depression, irritability and inability to concentrate are the general complaints of nervous system. The occurrence of allergies, chemical sensitivities and low immune function are also very frequent. A great majority of patients has shown, in the past history, one or more of these conditions: chronic vaginal yeast infections; chronic antibiotic use for infections or acne; oral birth control and oral steroid hormone usage, as well as premenstrual syndrome; sensibility to foods, chemicals and other allergens; endocrine disturbances; eczema; psoriasis; and irritable bowel syndrome. One of the most important aspects is that most patients have craving for foods rich in carbohydrates or yeast $[1,5,49,62]$.

Occasionally, patients saying that "feel sick all over" characterize the syndrome. It is important to consider that women patients have eight times more yeast infections compared to men, due to the effects of estrogen, birth control pills and the large number of antibiotics prescriptions [1, 5, 49, 62].

\section{Diagnosis Methods}

\section{Questionnaire}

Candida albicans questionnaire is one of the most useful screening methods to determine and understand the likelihood of yeast-related illness. It is composed by three sections: anamnesis, main symptoms and other symptoms. The complete evaluation is made by the sum of those sections, directing the treatment and establishing hierarchy of intervention. Although Candida questionnaire can be profitable, clinical evaluation is one of the most important and credible methods of diagnosis, including patient's history and clinical picture. Promptly, and according to the necessity, laboratory examinations, such as stool cultures for $C$. albicans and measurement of antibody levels or antigens in the body, are very useful and accurate [5, 43, 57].

\section{Comprehensive Digestive Stool Analysis (CDSA)}

The stool sample culture exam is very common, but it is inconclusive and provides little information in the case of active infection. CDSA is an extremely useful and effective method to determine the existence of some digestive disturbances, functional and clinical status of the GI tract, which can be one of the major responsible factors of Candida overgrowth. It also allows determination of the symptoms that are not related with Candida overgrowth, but associated with the intestinal bacteria overgrowth or presence of inflammatory bowel disease [57, 59, 60, 62, 89].

Comprehensive digestive stool analysis is also considered very important to maintain the optimal functioning and ecology of the GI tract to improve human health and wellness. This noninvasive method of diagnosis can be considered as an integrated tool. It provides advanced clinical insight and allows, carefully, an evaluation and examination not only of digestion, absorption and intestinal capacity or function, but also of intestinal environment, gut immunology and metabolism, microflora balance and colon risk cancer. Therefore, in the last instance, it is helpful in the diagnosis and monitorization of disease-specific infections or conditions, but also determines the etiology of diseases [57, 59, 60, 62, 89].

\section{Laboratorial Techniques of Diagnostic}

Laboratory techniques only confirm the patient's history, physical examination and CDSA, only few additional data are provided, and it is rarely used. However, there are situations in which the physician or the patients intend to objectify which Candida species is the main ethiogenic agent. In this case, microbiologic, molecular 
and biochemical assays could be used. For example, the blood analysis can be useful, not only as a method of determination/confirmation, as well as to monitoring therapy. This test is based on measuring the level of antibodies to Candida antigens. Other techniques, such as urine test, used to measure yeast metabolites and intestinal permeability, help to assess metabolic reasons for candidiasis [57, 59, 60, 62].

\section{Prevention}

Considering the facts described above, and being $C$. albicans a commensal microorganism and that is present in all people, it is important to control the number and magnitude of its population. As prevention is the most effective treatment, much more than the eradication of the yeast with antifungal agentssynthetic or naturals, it is fundamental to address and amend the predisposing factors. Therefore, maintaining a good personal hygiene is essential. Moreover, being woman more prone to this kind of infection, a good vaginal and oral hygiene is essential, in order to reduce the probability of candidiasis occurrence [5, $17,42,46,49,59,60]$. Some general guidelines for personal hygiene are listed in Table 1.

Since deep infections have been increasing, mainly in hospitals, the following aspects should be considered: probes and catheters should be regularly monitored and removed, as soon as possible; and the frequency, duration and amplitude of the quantities of antibiotics should be kept to a minimum [3, 6, 9, 14, 49, 72, 90].

Not less important is to avoid certain risk factors, such as diets rich in sugar and poor in vitamins and minerals, or the use of antibiotics.

\section{Alternative Treatment}

Candida albicans is an opportunistic yeast that cause infectious but, in some levels, lives and grows inside most human bodies. In normal situations, Candida is not harmful because our bodies are able to keep it under control, mainly by immune cells and probiotic bacteria. However, some factors previously discussed, such as allergies, high-sugar diets, medications/drugs and other factors that directly affect the normal balance of intestinal environment, can kill the friendly
Table 1 Main general guidelines for personal hygiene [49, 59, $60,62]$

\begin{tabular}{|c|c|}
\hline & Procedures \\
\hline $\begin{array}{l}\text { Superficial } \\
\text { infections }\end{array}$ & $\begin{array}{l}\text { Avoid contact with other body parts, as well } \\
\text { as with other persons } \\
\text { Maintain the skin clean and dry } \\
\text { During menstruation, compresses without } \\
\text { cosmetic products should be used }\end{array}$ \\
\hline $\begin{array}{l}\text { Vaginal } \\
\text { candidiasis }\end{array}$ & $\begin{array}{l}\text { Avoid frequent use of vaginal douches and } \\
\text { intimate hygiene products (they alter the } \\
\text { normal vaginal } \mathrm{pH} \text {, causing unbalance and } \\
\text { favoring the onset of infection) } \\
\text { Maintain external vaginal area completely } \\
\text { dry } \\
\text { Avoid prolonged use of bathing suit or damp } \\
\text { or wet underwear } \\
\text { The act of cleaning up should always be done } \\
\text { backward } \\
\text { Avoid sexual relations during antifungal } \\
\text { therapy }\end{array}$ \\
\hline $\begin{array}{l}\text { Personal } \\
\text { belongings }\end{array}$ & $\begin{array}{l}\text { Bed linen, bathroom and personal clothing } \\
\text { should be washed with very hot water, } \\
\text { separated from the others at home and } \\
\text { disinfected after use } \\
\text { Avoid tight clothing and use cotton } \\
\text { underwear }\end{array}$ \\
\hline
\end{tabular}

bacteria and stimulate the overgrowth of pathogenic microorganisms [1, 68, 69, 84, 87, 88]. Therefore, the best complementary treatment is to reduce and control Candida levels. Several recommendations/interventions are necessary according to each person. In most of the cases, direct therapy for Candida species destruction is advantageous, because it assists the body on lowering Candida species to controllable levels [49, 57, 59, 60]. However, depending on the profile of the patient, other procedures (diet and nutrition, enhancing immunity system, detoxification and natural antiyeast agents, Fig. 1) are required and will be discussed.

\section{Therapeutic Considerations}

\section{Diet and Nutrition}

As previously discussed, some dietary factors affect and promote the overgrowth of $C$. albicans; therefore, following a special diet for the treatment of candidiasis is crucial. The most important elements are refined sugars, such as sucrose, fruit juice, honey 
and other sweet foods, because $C$. albicans grows in sugar environments. Foods with high content of fungi or yeasts, such as alcoholic beverages, cheeses, dried fruits, bread and fermented products, should be avoided, as also milk and dairy products due to the high content of lactose and, in some cases, trace levels of antibiotics. Likewise, all the allergens present in food should be eliminated, since allergies weaken the immune system, promoting the growth of pathogens. There are several reasons to restrict or eliminate milk and other dairy products, not only for the high levels of lactose that promote Candida overgrowth, but also because it is one of the most frequent food allergens, and the presence of trace levels of antibiotics disrupts the GI bacterial flora [42, 55, 57, 59, 60, 70, 87].

Food allergies could be assessed by some immunoanalytical methods, such as ELISA tests, which determine both IgE- and IgG-mediated food allergies and often help in the identification of allergies [91-95].

Foods that can be eaten without problems and/or constraints are vegetables, sources of proteins, such as fish, meat and organic poultry, legumes and whole grains. The latter consumption is dependent of each individual tolerance. For fruits, although being the majority alkaline, the recommendation is to eliminate the consumption for a month of citrus and acidic fruits (e.g., oranges, grapefruit, lemons, tomatoes, pineapple and limes); afterward, the consumption can be made twice a week. Apples, cranberries, cherries, pears and other soft fruits can be daily consumed. Although the existence of conflicting opinions, the consumption of yogurt containing live probiotic cultures is recommended in order to replace friendly bacteria. In some cases, for vaginal candidiasis, a natural unprocessed and unsweetened yogurt can be applied directly into the vagina or a mixture of one small container of plain yogurt with an equal amount of water can be used as a douche, once or twice a day, until improvement is observed. Alternatively, or complementary, it is also possible to take supplemental acidophilus or bifidus, or to open two capsules of acidophilus and add the contents to a douche. It is also recommended to consume daily oat bran and/or flaxseed, not only as a source of fiber, being the latter also very effective due to antifungal properties [49, 57, 59, 60].

Table 2 summarizes the most important dietary aspects in fungal infections.
Table 2 Dietary considerations in the treatment of candidiasis $[57,59,60,62,97]$

\begin{tabular}{|c|c|c|}
\hline & $\begin{array}{l}\text { Food } \\
\text { characteristics }\end{array}$ & Food products \\
\hline \multirow[t]{4}{*}{ To avoid } & $\begin{array}{l}\text { Refined } \\
\text { carbohydrate } \\
\text { sources }\end{array}$ & $\begin{array}{l}\text { Refined sugars (sucrose, } \\
\text { fructose, corn syrup), fruit } \\
\text { juice, honey, maple syrup }\end{array}$ \\
\hline & $\begin{array}{l}\text { Fungi and/or } \\
\text { yeast sources }\end{array}$ & $\begin{array}{l}\text { Alcoholic beverages, dried } \\
\text { fruits, cheeses, peanut }\end{array}$ \\
\hline & $\begin{array}{l}\text { Lactose and } \\
\text { antibiotic } \\
\text { sources }\end{array}$ & Dairy products \\
\hline & $\begin{array}{l}\text { Allergenic } \\
\text { foods }\end{array}$ & $\begin{array}{l}\text { Dairy products, eggs, } \\
\text { chocolate, fried and } \\
\text { processed foods, wheat, } \\
\text { peanuts }\end{array}$ \\
\hline To limit & $\begin{array}{l}\text { Carbohydrate } \\
\text { sources }\end{array}$ & Corn and potatoes \\
\hline \multirow[t]{3}{*}{$\begin{array}{l}\text { To } \\
\text { consume }\end{array}$} & $\begin{array}{l}\text { Vitamin } \\
\text { sources }\end{array}$ & $\begin{array}{l}\text { Vegetables, fruits (apples, } \\
\text { pears, cranberries, cherries, } \\
\text { blueberries and other soft } \\
\text { fruit) }\end{array}$ \\
\hline & Protein sources & $\begin{array}{l}\text { Fish, meat and biological } \\
\text { poultry }\end{array}$ \\
\hline & Fiber sources & Whole grains, ground flaxseeds \\
\hline
\end{tabular}

\section{Enhancing Immune System}

In most cases of chronic candidiasis, the immune system is altered (mostly depressed) allowing a quick growth of C. albicans. This explains why the patients have repetitive cycles of infection that lead to increase damages and further resistance weakening. Thereby, it is very important to potentiate the immune function, in order to protect the organism against foreign/opportunist agents. Additionally, in patients suffering from AIDS or taking immunosuppressive drugs, the immune system is affected, which favors the $C$. albicans overgrowth. In both cases, the prevalence of candidiasis is considerable, being the strength of the immune function very important. In some cases, the debility of the immune system is related to a decrease in thymus function, represented by an impairment of cell-mediated immunity [57, 59]. There are some points that help to strength the immune function and that eliminate, suppress or amend the causes of depressed immune function. The major triggers of impaired immunity and that lead to $C$. albicans overgrowth are antibiotics, corticosteroids and other drugs that suppress immune system, as also nutrients 
deficiency, food allergies and stress $[1,37,40,53,69$, $75,80,84]$.

Accordingly, restoring proper immune function is one of the major objectives in the treatment of chronic candidiasis; to reach this goal, some strategies could be followed: stress management, diet restriction, nutritional supplementation, glandular therapy, exercise and the use of plant-based medicines. However, as the clinical remission of candidiasis is directly dependent on T-cells function, it is also crucial to improve thymus gland function. To achieve this, it is necessary to guarantee an adequate intake of antioxidants, through nutritional supplementation, such as carotenes, vitamins A, C and E, zinc and selenium. Some plants could be used to complement this intervention, namely Echinacea angustifolia, Hydrastis canadensis and Glycyrrhiza glabra [49, 57, 59, 62, 96].

\section{Detoxification}

The human body is continuously exposed to substances and toxic agents, which accumulates in the body. Therefore, the body detoxification process is continuous, being widely recognized that different substances (e.g., heavy metals, pesticides, microbial toxins and solvents) have considerable interferences in the health and well-being of individuals. The liver is an extremely important organ in the body, responsible for vascular, metabolic and secretory functions. In addition, it is also responsible for the detoxification of all the chemical substances at which we are constantly exposed (not only those ingested through diet and as a result of the environment interaction, but also those resulting from endogenous metabolic processes, such as drugs and other cellular metabolisms). It has been observed that the majority of subjects with $C$. albicans overgrowth present some problems in liver detoxification mechanisms. Moreover, the presence of multiple chemical sensibilities and allergies is frequent in patients with chronic candidiasis, which is a direct indicator of problems in detoxification reactions. The damage of liver is an underlying factor in chronic candidiasis, as well as in chronic fatigue, because when the liver is damaged by chemical toxins and others, the immune function is severely compromised. Thus, enhanced liver function is vital, not only before, but also during and even after procedures that destroy yeasts, in order to increase the likelihood of success in candidiasis treatment $[49,57,59,60,62]$.
Table 3 Procedures to improve liver function and detoxification $[49,57,59,60,97]$

\begin{tabular}{|c|c|}
\hline & Procedures \\
\hline \multirow[t]{5}{*}{$\begin{array}{l}\text { Improve liver } \\
\text { function }\end{array}$} & $\begin{array}{l}\text { Consuming garlic, onions, chlorella, } \\
\text { spirulina, wheatgrass; }\end{array}$ \\
\hline & $\begin{array}{l}\text { Diet based on fresh fruits and vegetables, } \\
\text { whole grains, legumes, nuts and seeds; }\end{array}$ \\
\hline & $\begin{array}{l}\text { Avoiding alcohol and adopt others healthy } \\
\text { lifestyles; }\end{array}$ \\
\hline & $\begin{array}{l}\text { Supplementation with a high-potency } \\
\text { multiple vitamin and minerals; }\end{array}$ \\
\hline & Regular exercise \\
\hline \multirow[t]{3}{*}{$\begin{array}{l}\text { Improve } \\
\text { detoxification }\end{array}$} & $\begin{array}{l}\text { Diet based on high-fiber plant foods to } \\
\text { supplying a high amount of dietary fiber; }\end{array}$ \\
\hline & $\begin{array}{l}\text { If necessary, prescribed additional fiber } \\
\text { formulas-3-5 g of soluble fiber at the } \\
\text { bedtime-composed by natural plant } \\
\text { fibers, derived from psyllium seed, kelp, } \\
\text { agar, pectin, guar and others that promote } \\
\text { a natural mechanism of bowel movement; }\end{array}$ \\
\hline & $\begin{array}{l}\text { Using lipotropic formulas }{ }^{\mathrm{a}} \text { such as choline, } \\
\text { betaine and methionine or cysteine, } \\
\text { silymarin to protect the liver }\end{array}$ \\
\hline
\end{tabular}

a The importance of lipotropic factors is related to increased levels of two important liver substances: SAMs ( $S$ adenosylmethionine) and glutathione that are the major lipotropic and detoxifying compounds in the liver, respectively

Some procedures could help in the improvement of detoxification process by liver (Table 3 ).

\section{Natural Antiyeast Agents}

Natural antiyeast agents with proven activity against C. albicans can be used to treat the infection concomitantly to other procedures. Nevertheless, to be effective as primary therapy, predisposing factors to chronic candidiasis, diet and lifestyle should also be taken into account. The most studied compounds that act as natural agents against $C$. albicans are caprylic acid; berberine-containing plants; probiotics; grapefruit seed extract; garlic; tea tree oil; and entericcoated volatile oil preparations containing oregano, thyme, peppermint and rosemary; propolis; ginger and cinnamon. However, the occurrence of Herxheimer reaction is very frequent when an effective antiyeast therapy is used, due to the rapid elimination of the microorganisms and subsequent absorption of large amounts of yeast toxins, cell particles and antigens. The mentioned reaction can be eliminated through 
supporting liver function, following dietary recommendations and starting antiyeast medications in low and gradually increasing doses [49, 57, 59, 60, 97].

\section{Therapeutic Approach}

In order to successively control the growth of $C$. albicans and related infections (candidiasis), a therapeutic intervention is required.

After identification of the predisposing factors, it is essential to develop a diet to control C. albicans growing. The most commonly used substances and phytotherapics in the complementary treatment of candidiasis are presented in Table 4.

Besides the mentioned phytotherapics, there are other plants with documented antifungal activity, particularly against $C$. albicans, such as essential oils from ginger (Zingiber officinale) [98-100], cassia (Cinnamomum cassia) $[98,101]$ and others Cinnamomum species [32, 102], chamomile (Matricaria chamomilla) [57, 103, 104], lemon balm (Melissa officinalis) [32, 101, 105], thymus (Thymus vulgaris) and rosemary (Rosmarinus officinalis) [101, 106-109].

Nevertheless, there are still several unknown compounds from plants that could act synergistically, among themselves and with other natural compounds, against yeast infections [57, 59, 60, 97, 110].

Other aspects should also be considered, namely rest and liquids intake mainly vegetable diluted juices, soups and plant infusions. Moreover, it is necessary to promote a positive mind and help patients to cope stress. Alcohol, simple sugars, tobacco and cholesterol should be avoided due to their capacity of stimulating C. albicans overgrowth and impair the immune function. The support to thymus gland function is also provided by $500 \mathrm{mg}$ of crude polypeptide fractions, twice daily [57, 59, 60, 62, 96, 111].

The body ability to detoxify and eliminate some substances is mostly dependent of healthy diet and lifestyle. As previously mentioned, liver is the responsible for the detoxification of all chemical substances. Therefore, the optimization of liver

Table 4 Substances and phytochemicals commonly used in alternative treatment of candidiasis

\begin{tabular}{|c|c|c|}
\hline \multicolumn{2}{|l|}{ Substance } & Dosage/description \\
\hline \multirow{2}{*}{\multicolumn{2}{|c|}{$\begin{array}{l}\text { High-potency complex of multivitamins and minerals formula } \\
\text { Zinc picolinate }\end{array}$}} & Hypoallergenic formulas, free of yeasts \\
\hline & & $45 \mathrm{mg} /$ day \\
\hline \multicolumn{2}{|l|}{ Selenium } & $200 \mu \mathrm{g} /$ day \\
\hline \multicolumn{2}{|l|}{ Caprylic acid } & Formula of slow liberation ( $1 \mathrm{~g}$ with meals) \\
\hline \multicolumn{2}{|l|}{ Probiotics (intestinal flora) } & Products containing Lactobacillus \\
\hline \multicolumn{2}{|l|}{ Fiber supplement } & Guar gum, pectin or psyllium seeds ( 1 teaspoon before bedtime) \\
\hline \multicolumn{2}{|l|}{ Phytotherapics } & /description \\
\hline \multirow{2}{*}{$\begin{array}{l}\text { Tabebuia impetiginosa (lapacho) } \\
\text { Berberis vulgaris (barberry) }\end{array}$} & \multicolumn{2}{|r|}{$15-20 \mathrm{~g}$ of bark in $0.5 \mathrm{~L}$ boiling water for $5-15 \mathrm{~min}, 3-4$ times/day; } \\
\hline & \multicolumn{2}{|c|}{ The following doses, 3 times/day } \\
\hline & \multicolumn{2}{|c|}{ Dried bark of the root (as tea): 1-2 g } \\
\hline & \multicolumn{2}{|c|}{ Tincture (1:5): 4-6 mL (1-1 and $1 / 2$ teaspoon) } \\
\hline & \multicolumn{2}{|c|}{ Liquid extract (1:1): $0.5-2 \mathrm{~mL}(1 / 4-1 / 2$ teaspoon $)$} \\
\hline & \multicolumn{2}{|c|}{ Powdered solid extract (4:1): $250-500 \mathrm{mg}$} \\
\hline \multirow[t]{5}{*}{ Hydrastis Canadensis (goldenseal) } & \multicolumn{2}{|c|}{ The following doses, 3 times/day } \\
\hline & \multicolumn{2}{|c|}{ Dried root (as tea): $1-2 \mathrm{~g}$} \\
\hline & \multicolumn{2}{|c|}{ Tincture (1:5): 4-6 mL (1-1 and $1 / 2$ teaspoon) } \\
\hline & \multicolumn{2}{|c|}{ Liquid extract (1:1): $0.5-2 \mathrm{~mL}(1 / 4-1 / 2$ teaspoon $)$} \\
\hline & \multicolumn{2}{|c|}{ Powdered solid extract (4:1): $250-500 \mathrm{mg}$} \\
\hline Origanum vulgare (oregano) oil & \multicolumn{2}{|r|}{$\begin{array}{l}\text { 300-500 mg by capsule or liquid form, } 3 \text { times/day, with meals to avoid } \\
\text { digestive unease }\end{array}$} \\
\hline Allium sativum (garlic) & \multicolumn{2}{|r|}{$\begin{array}{l}\text { Actual guidelines based on allin }(10 \mathrm{mg}) \text { and allicin }(4,000 \mu \mathrm{g}) \text {, which is } \\
\text { equivalent to } 4,000 \mathrm{mg} \text { of fresh garlic or } 500-1,000 \mathrm{mg} \text { of aged garlic }\end{array}$} \\
\hline Citrus paradise (grapefruit) seed extract & \multicolumn{2}{|c|}{$200 \mathrm{mg}, 2-3$ times/day } \\
\hline
\end{tabular}


function, promoting their protection and using lipotropic factors, accelerates the elimination and fat deposition in liver, and could offer significant benefits [57, 59, 60, 97]. In some cases, the use of formulas containing natural plant fibers derived from psyllium seed, kelp, agar, pectin and plant gums is necessary to help elimination of toxic substances and protect the bowel wall from irritation. Moreover, these fiber formulas promote natural bowel movements, and if antiyeast therapies are employed, they guarantee that dead yeast cells are excreted and not absorbed; 3-5 g of soluble fiber at bedtime is required for the treatment of candidiasis [57, 59, 60, 87, 88, 112, 113].

The repair of intestinal flora is another crucial factor. Particularly, Lactobacilus acidophilus, Bifidobacterium bifidum, Lactobacillus bulgaricus and Streptococcus thermophilus are very important, not only as antifungals, antibacterials and antivirals, but also in digestion and in production of vitamins and other substances important to maintain gut and the all body healthy. The recommendation is a product containing 4-10 billion viable active organisms, $30 \mathrm{~min}$ after a meal. However, some foods, such as yogurt and kefir, could also be a good source of probiotics, but is necessary to take care, mainly due to fact that the yogurt itself does not have the necessary amount of bacteria, and in other hand, the presence of sugar promotes the overgrowth of $C$. albicans and other microorganisms. Therefore, the yogurt should have the proper bacteria and should not be sweetened [57, 59, 60, 87, 88, 112, 113].

Lastly, the use of nutritional supplements or herbs seems to be the best option to help and control $C$. albicans overgrowth, and to promote a healthy bacterial flora. Antifungal drugs should be prescribed only if necessary. In most cases, these therapeutic interventions are effective to threat candidiasis, including chronic candidiasis. However, if the patient cannot achieve a significant improvement and/or eradicate the infection, it is necessary to perform a deeper evaluation $[57,59,60,62]$. If the organism is still present, after repeat stool cultures and measure antigen levels, antibiotics could be prescribed, combined with other recommendations [57, 59, 60]. Despite until now the majority of studies focused essentially in the role of oils of plants, currently other natural matrices preparations have been studied, namely aqueous and alcoholic extracts. It is very important to underline that the use of plants and other botanical preparations are used, since ancient times, by primitive societies, due to healing properties and therapeutic and psychotherapeutic benefits. It is important to address the fact that plants are widely used to obtain a large variety of drugs, being used in folk medicine for a long time [26-29, 32-35]. Concerning that plants represent an economic, easily and which are accessible for all of people, they can be used into a variety of diseases, constituting an excellent source of biomolecules able to act like natural antifungal agents and, at the same time, to encourage the search for other alternative treatments. They can be used both to complement a conventional treatment with antifungal agents and singly like a natural alternative treatment. In both situations, the counseling and following of a growing control diet are crucial to ensure successful of therapy.

Moreover, despite the increasing interest of several studies toward the identification of several compounds with therapeutic potential and their synergistic effect, in combination with other compounds, many properties of plants remain unknown, as well as their main compounds. Thus, not only it is necessary to deepen the study of other preparations of known plants but also to investigate other therapeutic effects provided by plants and the major responsible compounds.

\section{Concluding Remarks}

All people are exposed to a variety of candidiasis predisposing factors, and some of them are impossible to avoid. Candidiasis can affect different parts of the body (nails, GI tract and vagina, among others) being characterized by several symptoms, which oftendifficult diagnosis; additionally, the individual characteristics alter the manifestation of signals and symptoms. As this infection is very uncomfortable and, in some cases, offers a considerable health risk, the major and most important aspect is prevention. Therefore, there are several aspects to consider and include in the daily routine, which at first might seem insignificant, but that could provide a strength protection.

To combat the infection, different procedures are necessary according to the pathologic conditions of the patient; if all daily care is considered, the probability of the infection occurrence will be considerably reduced. However, in face of an infection, a 
rapid intervention is necessary, and for this, other alternatives to antifungals and antimicrobials are necessary.

Acknowledgments The authors are grateful to Foundation for Science and Technology (FCT, Portugal) for N. Martins grant (SFRH/BD/87658/2012), L. Barros researcher contract under "Programa Compromisso com Ciência-2008" and financial support to the research center CIMO (strategic project PEst-OE/ AGR/UI0690/2011).

\section{References}

1. Vázquez-González D, Perusquía-Ortiz AM, Hundeiker M, Bonifaz A. Opportunistic yeast infections: candidiasis, cryptococcosis, trichosporonosis and geotrichosis. J Ger Soc Dermatol. 2013;11:381-94. http://www.ncbi.nlm.nih. gov/pubmed/23621330.

2. McCullough MJ, Ross BC, Reade PC. Candida albicans: a review of its history, taxonomy, epidemiology, virulence attributes, and methods of strain differentiation. Int J Oral Maxillofac Surg. 1996;25:136-44. http://www.ncbi.nlm. nih.gov/pubmed/8727588.

3. Brunke S, Hube B. Two unlike cousins: Candida albicans and C. glabrata infection strategies. Cell Microbiol. 2013; 15:701-8. http://www.pubmedcentral.nih.gov/articlerender. fcgi?artid $=3654559 \&$ tool $=$ pmcentre $\&$ rendertype $=$ abstract.

4. Wächtler B, Citiulo F, Jablonowski N, Förster S, Dalle F, Schaller M, et al. Candida albicans-epithelial interactions: dissecting the roles of active penetration, induced endocytosis and host factors on the infection process. PLoS One. 2012;7:1-10. http://www.pubmedcentral.nih. gov/articlerender.fcgi artid=3351431\&tool=pmcentrez \& rendertype $=$ abstract.

5. Greenberg MS, Glick M. Burket's oral medicine: diagnosis and treatment. 10th ed. USA: BC Decker Inc.; 2003. p. 658.

6. Eggimann P, Garbino J, Pittet D. Epidemiology of Candida species infections in critically ill non-immunosuppressed patients. Lancet Infect. Dis. 2003;3:685-702.

7. Abi-Said D, Anaissie E, Uzun O, Raad I, Pinzcowski H, Vartivarian S. The epidemiology of hematogenous candidiasis caused by different Candida species. Clin Infect Dis. 1997;24:1122-8. http://www.ncbi.nlm.nih.gov/pubmed/ 9195068.

8. Raman SB, Nguyen MH, Cheng S, Badrane H, Iczkowski $\mathrm{KA}$, Wegener M, et al. A competitive infection model of hematogenously disseminated candidiasis in mice redefines the role of Candida albicans IRS4 in pathogenesis. Infect Immun. 2013;81:1430-8. http://www.ncbi.nlm.nih. gov/pubmed/23429534.

9. Mayer FL, Wilson D, Hube B. Candida albicans pathogenicity mechanisms. Virulence. 2013;4:119-28. http:// www.pubmedcentral.nih.gov/articlerender.fcgi?artid=365 4610\&tool $=$ pmcentrez\&rendertype $=$ abstract.

10. Tsai P-W, Chen Y-T, Hsu P-C, Lan C-Y. Study of Candida albicans and its interactions with the host: a mini review. BioMedicine. Elsevier Taiwan LLC;
2013;3:51-64. http://linkinghub.elsevier.com/retrieve/ pii/S2211802012000824.

11. Li SY, Yang YL, Chen KW, Cheng HH, Chiou CS, Wang $\mathrm{TH}$, et al. Molecular epidemiology of long-term colonization of Candida albicans strains from HIV-infected patients. Epidemiol Infect. 2006;134:265-9. http://www. pubmedcentral.nih.gov/articlerender.fcgi? artid=2870383 $\&$ tool $=$ pmcentrez\&rendertype $=$ abstract.

12. Fanello S, Bouchara JP, Jousset N, Delbos V, LeFlohic AM. Nosocomial Candida albicans acquisition in a geriatric unit: epidemiology and evidence for person-to-person transmission. J Hosp Infect. 2001;47:46-52. http://www. ncbi.nlm.nih.gov/pubmed/11161898.

13. Kim J, Sudbery P. Candida albicans, a major human fungal pathogen. J Microbiol. 2011;49:171-7. http://www. ncbi.nlm.nih.gov/pubmed/21538235.

14. Department of Surgical Education-Orlando RegionalMedical Center. Management of Candida infections in surgical patients. Orlando-Florida, USA. 2002. p. 1-10.

15. Silva S, Henriques M, Hayes A, Oliveira R, Azeredo J, Williams DW. Candida glabrata and Candida albicans co-infection of an in vitro oral epithelium. J Oral Pathol Med. 2011;40:421-7. http://www.ncbi.nlm.nih.gov/pubmed/ 21158929.

16. McCullough MJ, Clemons KV, Stevens DA. Molecular epidemiology of the global and temporal diversity of Candida albicans. Clin Infect Dis. 1999;29:1220-5. http:// www.ncbi.nlm.nih.gov/pubmed/10524966.

17. Develoux M, Bretagne S. Candidoses et levuroses diverses. EMC Mal Infect. 2005;2:119-39. http://linkinghub.elsevier. com/retrieve/pii/S1638623X05000053.

18. Lott TJ, Fundyga RE, Kuykendall RJ, Arnold J. The human commensal yeast, Candida albicans, has an ancient origin. Fungal Genet Biol. 2005;42:444-51. http://www. ncbi.nlm.nih.gov/pubmed/15809008.

19. Uppuluri P, Chaturvedi AK, Srinivasan A, Banerjee M, Ramasubramaniam AK, Köhler JR, et al. Dispersion as an important step in the Candida albicans biofilm developmental cycle. PLoS Pathog. 2010;6:1-13. http://www. pubmedcentral.nih.gov/articlerender.fcgi?artid= 2847914\&tool=pmcentrez\&rendertype $=$ abstract.

20. Silva S, Henriques M, Oliveira R, Williams D, Azeredo J. In vitro biofilm activity of non-Candida albicans Candida species. Curr Microbiol. 2010;61:534-40. http://www. ncbi.nlm.nih.gov/pubmed/20401483.

21. Sardi JCO, Scorzoni L, Bernardi T, Fusco-Almeida AM, Mendes Giannini MJS. Candida species: current epidemiology, pathogenicity, biofilm formation, natural antifungal products and new therapeutic options. J Med Microbiol. 2013;62:10-24. http://www.ncbi.nlm.nih.gov/ pubmed/23180477.

22. Ferreira AV, Prado CG, Carvalho RR, Dias KST, Dias ALT. Candida albicans and non-C. albicans Candida species: comparison of biofilm production and metabolic activity in biofilms, and putative virulence properties of isolates from hospital environments and infections. Mycopathologia. 2013;175:265-72. http://www.ncbi.nlm.nih. gov/pubmed/23532754.

23. González ID-C, González FG-B, Cuesta TS, Fernández JM, Rodríguez JMD-A, Ferrairo RAE, et al. Patient preferences and treatment safety for uncomplicated 
vulvovaginal candidiasis in primary health care. BMC Public Health. BioMed Central Ltd; 2011;11:1-8. http:// www.pubmedcentral.nih.gov/articlerender.fcgi?artid=304 $8533 \&$ tool=pmcentrez\&rendertype $=$ abstract.

24. Sanglard D, Odds FC. Reviews resistance of Candida species to antifungal agents: molecular mechanisms and clinical consequences. Lancet Infect. Dis. 2002;2:73-85.

25. Kanafani ZA, Perfect JR. Resistance to antifungal agents: mechanisms and clinical impact. Clin Infect Dis Antimicrob Resist. 2008;46:120-8. http://www.ncbi.nlm.nih. gov/pubmed/18171227.

26. Alves-Silva JM, dos Santos SMD, Pintado ME, PérezÁlvarez JA, Fernández-López J, Viuda-Martos M. Chemical composition and in vitro antimicrobial, antifungal and antioxidant properties of essential oils obtained from some herbs widely used in Portugal. Food Control. Elsevier Ltd; 2013;32:371-8. http://linkinghub.elsevier. com/retrieve/pii/S0956713513000030.

27. Silva F, Ferreira S, Duarte A, Mendonça DI, Domingues FC. Antifungal activity of Coriandrum sativum essential oil, its mode of action against Candida species and potential synergism with amphotericin B. Phytomedicine. 2011;19:42-7. http://www.ncbi.nlm.nih.gov/pubmed/21788125.

28. Rana IS, Rana AS, Rajak RC. Evaluation of antifungal activity in essential oil of the Syzygium aromaticum (L.) by extraction, purification and analysis of its main component eugenol. Braz J Microbiol. 2011;42:1269-77.

29. Agarwal V, Lal P, Pruthi V. Effect of plant oils on Candida albicans. J Microbiol Immunol Infect. Taiwan Society of Microbiology; 2010;43:447-51. http://www.ncbi.nlm.nih. gov/pubmed/21075713.

30. Asl MN, Hosseinzadeh H. Review of pharmacological effects of Glycyrrhiza sp. and its bioactive compounds. Phytother Res. 2008;22:709-24.

31. Shojaii A, Abdollahi Fard M. Review of pharmacological properties and chemical constituents of Pimpinella anisum. Int Sch Res Netw ISRN Pharm. 2012;1-8. http:// www.pubmedcentral.nih.gov/articlerender.fcgi?artid=340 $5664 \&$ tool=pmcentrez\&rendertype $=$ abstract.

32. Bakkali F, Averbeck S, Averbeck D, Idaomar M. Biological effects of essential oils-a review. Food Chem Toxicol. 2008;46:446-75. http://www.ncbi.nlm.nih.gov/ pubmed/17996351.

33. Singh A, Duggal S, Kaur N, Singh J. Berberine: alkaloid with wide spectrum of pharmacological activities. J Nat Prod. 2010;3:64-75.

34. Asgarpanah J, Kazemivash N. Phytochemistry, pharmacology and medicinal properties of Coriandrum sativum L. Afr J Pharm Pharmacol. 2012;6:2340-5. http://www. academicjournals.org/AJPP/abstracts/abstracts/ abstract2012/22Aug/AsgarpanahandKazemivash.htm.

35. Sher A. Antimicrobial activity of natural products from medicinal plants. Gomal J Med Sci. 2009;7:72-8.

36. Lewis LE, Bain JM, Lowes C, Gow NAR, Erwig L-P. Candida albicans infection inhibits macrophage cell division and proliferation. Fungal Genet Biol. Elsevier Inc.; 2012;49:679-80. http://www.pubmedcentral.nih.gov/ articlerender.fcgi?artid=3430961\&tool=pmcentrez\&render type $=$ abstract.

37. Kwamin F, Nartey NO, Codjoe FS, Newman MJ. Distribution of Candida species among HIV-positive patients with oropharyngeal candidiasis in Accra, Ghana. J Infect Dev Ctries. 2013;7:041-5.

38. Westwater C, Schofield DA, Nicholas PJ, Paulling EE, Balish E. Candida glabrata and Candida albicans; dissimilar tissue tropism and infectivity in a gnotobiotic model of mucosal candidiasis. FEMS Immunol Med Microbiol. 2007;51:134-9. http://www.ncbi.nlm.nih.gov/ pubmed/17854475.

39. Sullivan DJ, Moran GP, Pinjon E, Almosaid A, Stokes C, Vaughan C, et al. Comparison of the epidemiology, drug resistance mechanisms, and virulence of Candida dubliniensis and Candida albicans. FEMS Yeast Res. 2004;4: 369-76. http://linkinghub.elsevier.com/retrieve/pii/S1567 13560300240X.

40. Epstein JB, Polsky B. Oropharyngeal candidiasis: a review of its clinical spectrum and current therapies. Clin Ther. 1998;20:40-57. http://www.ncbi.nlm.nih.gov/pubmed/ 9522103.

41. Calderone RA, Fonzi WA. Virulence factors of Candida albicans. Trends Microbiol. 2001;9:327-35. http://www. ncbi.nlm.nih.gov/pubmed/11435107.

42. Sobel JD. Vulvovaginal candidosis. Lancet. 2007;369: 1961-71. http://www.ncbi.nlm.nih.gov/pubmed/17560449.

43. Rad MM, Zafarghandi S, Abbasabadi B, Tavallaee M. The epidemiology of Candida species associated with vulvovaginal candidiasis in an Iranian patient population. Eur J Obstet Gynecol Reprod Biol. Elsevier Ireland Ltd; 2011;155: 199-203. http://www.ncbi.nlm.nih.gov/pubmed/21194828.

44. Tarry W, Fisher M, Shen S, Mawhinney M. Candida albicans: the estrogen target for vaginal colonization. J Surg Res. 2005;129:278-82. http://www.ncbi.nlm.nih. gov/pubmed/16111702.

45. Geiger AM, Foxman B, Sobel JD. Chronic vulvovaginal candidiasis: characteristics of women with Candida albicans, C. glabrata and no Candida. Genitourin Med. 1995; 71:304-7. http://www.pubmedcentral.nih.gov/articlerender. fcgi?artid=1195546\&tool=pmcentrez\&rendertype=abstract.

46. Ahmad A, Khan AU. Prevalence of Candida species and potential risk factors for vulvovaginal candidiasis in Aligarh, India. Eur J Obstet Gynecol Reprod Biol. 2009;144: 68-71. http://www.ncbi.nlm.nih.gov/pubmed/19261369.

47. Liu XP, Fan SR, Bai FY, Li J, Liao QP. Antifungal susceptibility and genotypes of Candida albicans strains from patients with vulvovaginal candidiasis. Mycoses. 2009;52: 24-8. http://www.ncbi.nlm.nih.gov/pubmed/18498300.

48. David LM, Walzman M, Rajamanoharan S. Genital colonisation and infection with candida in heterosexual and homosexual males. Genitourin Med. 1997;73:394-6. http://www.pubmedcentral.nih.gov/articlerender.fcgi?artid $=1195901 \&$ tool $=$ pmcentrez\&rendertype $=$ abstract.

49. Longe JL. Yeast infection. The Gale encyclopedia of alternative medicine, vol 4. 2nd ed. Blanchfield DS, Fundukian L, Watts E, editors. USA: Thomson GALE; 2005.

50. McGirt LY, Martins CR. Dermatologic diagnoses in the perianal area. Clin Colon Rectal Surg. 2004;17:241-5. http://www.pubmedcentral.nih.gov/articlerender.fcgi?artid $=2780053 \&$ tool $=$ pmcentrez\&rendertype $=$ abstract.

51. de Wet PM, Rode H, Van Dyk A, Millar AJW. Candidiasis perianal-estudio comparativo de mupirocina y nistatina. Int J Dermatol. 1999;38:618-22. 
52. Mårdh P-A, Novikova N, Stukalova E. Colonisation of extragenital sites by Candida in women with recurrent vulvovaginal candidosis. BJOG. 2003;110:934-7. http:// www.ncbi.nlm.nih.gov/pubmed/14550364.

53. Okada M, Hisajima T, Ishibashi H, Miyasaka T, Abe S, Satoh T. Pathological analysis of the Candida albicansinfected tongue tissues of a murine oral candidiasis model in the early infection stage. Arch Oral Biol. Elsevier Ltd; 2013;58:444-50. http://www.ncbi.nlm.nih.gov/pubmed/ 23092606.

54. Dronda F, Alonso-Sanz M, Laguna F, Chaves F, MartínezSuárez JV, Rodríguez-Tudela JL, et al. Mixed oropharyngeal candidiasis due to Candida albicans and nonalbicans Candida strains in HIV-infected patients. Eur J Clin Microbiol Infect Dis. 1996;15:446-52. http://www. ncbi.nlm.nih.gov/pubmed/8839637.

55. Jin Y, Samaranayake LP, Samaranayake Y, Yip HK. Biofilm formation of Candida albicans is variably affected by saliva and dietary sugars. Arch Oral Biol. 2004;49: 789-98. http://www.ncbi.nlm.nih.gov/pubmed/15308423.

56. Asmundsdóttir LR, Erlendsdóttir H, Agnarsson BA, Gottfredsson $M$. The importance of strain variation in virulence of Candida dubliniensis and Candida albicans: results of a blinded histopathological study of invasive candidiasis. Clin Microbiol Infect. 2009;15:576-85. http:// www.ncbi.nlm.nih.gov/pubmed/19604278.

57. Murray MT, Pizzorno J. Enciclopedia de Medicina Natural. 2a Edicion. Domingo J, editor. Espanha: Ediciones Tutor S.A.; 1998. p. 638.

58. Rubinstein E, Mark Z, Haspel J, Ben-Ari G, Dreznik Z, Mirelman D, et al. Antibacterial activity of the pancreatic fluid. Gastroenterology. 1989;88:927-32.

59. Balch PA. Prescription for nutritional healing. 4th ed. Avery, editor. London: Penguin Group; 2006. p. 869.

60. Balch JF, Stengler M. Prescription for natural cures. John Wiley \& Sons I, editor. New Jersey; 2004. p. 724.

61. Brock JH. Lactoferrin in human milk: its role in iron absorption and protection against enteric infection in the newborn infant. Arch Dis Child. 1980;55:417-21. http:// www.pubmedcentral.nih.gov/articlerender.fcgi?artid=162 6933\&tool=pmcentrez\&rendertype $=$ abstract.

62. Pizzorno Jr. JE, Murray MT, Joiner-Bey H. Manual de Medicina Natural: Toma de decisiones en la clinica. 2nd ed. Elsevier, editor. Barcelona, Espanha: Churchill Livingstone; 2009. p. 824.

63. Serrano R, Bernal D, Simón E, Ariño J. Copper and iron are the limiting factors for growth of the yeast Saccharomyces cerevisiae in an alkaline environment. J Biol Chem. 2004;279:19698-704. http://www.ncbi.nlm.nih.gov/pubmed/ 14993228.

64. Pas M, Piskur B, Sustaric M, Raspor P. Iron enriched yeast biomass - a promising mineral feed supplement. Bioresour Technol. 2007;98:1622-8. http://www.ncbi.nlm.nih. gov/pubmed/16935492.

65. Prevorovský M, Stanurová J, Půta F, Folk P. High environmental iron concentrations stimulate adhesion and invasive growth of Schizosaccharomyces pombe. FEMS Microbiol Lett. 2009;293:130-4. http://www.ncbi.nlm. nih.gov/pubmed/19222572.

66. Lan C-Y, Rodarte G, Murillo LA, Jones T, Davis RW, Dungan J, et al. Regulatory networks affected by iron availability in Candida albicans. Mol Microbiol. 2004; 53:1451-69. http://www.ncbi.nlm.nih.gov/pubmed/1538 7822.

67. Schenkels LCPM, Veerman ECI, Amerongen AVN. Biochemical composition of human saliva in relation to other mucosal fluids. Crit Rev Oral Biol Med. 1995;6:161-75. http://cro.sagepub.com/cgi/doi/10.1177/104544119500 60020501.

68. Kim J, Han BJ, Kim H, Lee JY, Joo I, Omer S, et al. Th1 immunity induction by ginsenoside $\mathrm{Re}$ involves in protection of mice against disseminated candidiasis due to Candida albicans. Int Immunopharmacol. Elsevier B.V.; 2012;14:481-6. http://www.ncbi.nlm.nih.gov/pubmed/22 940185 .

69. Blanco JL, Garcia ME. Immune response to fungal infections. Vet Immunol Immunopathol. 2008;125:47-70. http://www.ncbi.nlm.nih.gov/pubmed/18565595.

70. Eggimann P, Garbino J, Pittet D. Management of Candida species infections in critically ill patients. Lancet Infect. Dis. 2003;3:772-85.

71. Chi H-W, Yang Y-S, Shang S-T, Chen K-H, Yeh K-M, Chang F-Y, et al. Candida albicans versus non-albicans bloodstream infections: the comparison of risk factors and outcome. J Microbiol Immunol Infect. Elsevier Taiwan LLC; 2011;44:369-75. http://www.ncbi.nlm.nih.gov/pub $\mathrm{med} / 21524971$.

72. Wroblewska MM, Swoboda-Kopec E, Rokosz A, Krawczyk E, Marchel H, Luczak M. Epidemiology of clinical isolates of Candida albicans and their susceptibility to triazoles. Int J Antimicrob Agents. 2002;20:472-5. http:// www.ncbi.nlm.nih.gov/pubmed/12458145.

73. Abe F, Katoh T, Inaba H, Hotchi M. Experimental candidiasis associated with liver injury-role of transferrin. Mycopathologia. 1988;104:3-6.

74. Abe F, Nagata S, Hotchi M. Experimental candidiasis in liver injury. Mycopathologia. 1987;100:37-42. http:// www.ncbi.nlm.nih.gov/pubmed/2975353.

75. Katiraee F, Khosravi AR, Khalaj V, Hajiabdolbaghi M, Khaksar A, Rasoolinejad M, et al. Oropharyngeal candidiasis and oral yeast colonization in Iranian Human Immunodeficiency Virus positive patients. J Mycol Med. Elsevier Masson SAS; 2010;20:8-14. http://linkinghub. elsevier.com/retrieve/pii/S1156523309001164.

76. Kontoyiannis DP, Lewis RE. Antifungal drug resistance of pathogenic fungi. Lancet. 2002;359:1135-44. http://www. ncbi.nlm.nih.gov/pubmed/11943280.

77. Gerard R, Sendid B, Colombel JF, Poulain D, Jouault T. An immunological link between Candida albicans colonization and Crohn's disease. Crit Rev Microbiol. 2013; $1-5$.

78. Kumamoto CA. Inflammation and gastrointestinal Candida colonization. Curr Opin Microbiol. Elsevier Ltd; 2011;14:386-91. http://www.pubmedcentral.nih.gov/artic lerender.fcgi? artid=3163673\&tool=pmcentrez\&rendertype $=$ abstract.

79. Trojanowska D, Zwolinska-Wcislo M, Tokarczyk M, Kosowski K, Mach T, Budak A. The role of Candida in inflammatory bowel disease. Estimation of transmission of C. albicans fungi in gastrointestinal tract based on genetic affinity between strains. Int Med J Exp Clin Res. 2010; 16:451-7. 
80. García-Ruiz JC, Amutio E, Ponton J. Infección fúngica invasora en pacientes inmunodeficientes. Rev Iberoam Micol. 2004;21:55-62.

81. Jawhara S, Thuru X, Standaert-Vitse A, Jouault T, Mordon $\mathrm{S}$, Sendid B, et al. Colonization of mice by Candida albicans is promoted by chemically induced colitis and augments inflammatory responses through galectin-3. J Infect Dis. 2008;197:972-80. http://www.ncbi.nlm.nih. gov/pubmed/18419533.

82. Standaert-Vitse A, Jouault T, Vandewalle P, Mille C, Seddik M, Sendid B, et al. Candida albicans is an immunogen for anti-Saccharomyces cerevisiae antibody markers of Crohn's disease. Gastroenterology. 2006;130:1764-75. http://www. ncbi.nlm.nih.gov/pubmed/16697740.

83. Sendid B, Jouault T, Vitse A, Fradin C, Colombel JF, Poulain D. Glycannes pariétaux de levures et anticorps spécifiques. MS Med Sci. 2009;25:473-81.

84. Rehaume LM, Jouault T, Chamaillard M. Lessons from the inflammasome: a molecular sentry linking Candida and Crohn's disease. Trends Immunol. Elsevier Ltd; 2010;31: 171-5. http://www.ncbi.nlm.nih.gov/pubmed/20149741.

85. Gerard R, Sendid B, Techy A, Vernier-Massouille G, Jouault T, Francois N, et al. Candida albicans colonization and anti-glycan antibodies in active and quiescent Crohn's disease. J Crohn's Colitis. European's Crohn's and Colitis Organisation; 2013:S290-1. http://linkinghub.elsevier. com/retrieve/pii/S1873994613607187.

86. McKenzie H, Main J, Pennington CR, Parratt D. Antibody to selected strains of Saccharomyces cerevisiae (baker's and brewer's yeast) and Candida albicans in Crohn's disease. Gut. 1990;31:536-8. http://gut.bmj.com/cgi/doi/ 10.1136/gut.31.5.536.

87. García-elorriaga G, Rey-pineda G. Nutrition and intestinal microflora. J Nutr Ther. 2013;2:112-21.

88. Isolauri E, Kirjavainen PV, Salminen S. Probiotics: a role in the treatment of intestinal infection and inflammation? Gut. 2002; 50:54-9. http://www.pubmedcentral.nih.gov/articlerender.fc gi $?$ artid=1867676\&tool=pmcentre $\&$ rendertype $=$ abstract.

89. Diagnostics G. Diagnostic laboratory testing for wellness \& preventive medicine. 2013. http://www.gdx.net/product/ 10006.

90. Tamura NK, Negri MFN, Bonassoli LA, Svidzinski TIE. Virulence factors for Candida spp recovered from intravascular catheters and hospital workers' hands. Rev Soc Bras Med Trop. 2007;40:91-3.

91. Birmingham N, Payankaulam S, Thanesvorakul S, Stefura B, HayGlass K, Gangur V. An ELISA-based method for measurement of food-specific IgE antibody in mouse serum: an alternative to the passive cutaneous anaphylaxis assay. J Immunol Methods. 2003;275:89-98. http://linking hub.elsevier.com/retrieve/pii/S0022175903000085.

92. Schubert-Ullrich P, Rudolf J, Ansari P, Galler B, Führer M, Molinelli A, et al. Commercialized rapid immunoanalytical tests for determination of allergenic food proteins: an overview. Anal Bioanal Chem. 2009;395:69-81. http:// www.ncbi.nlm.nih.gov/pubmed/19308361.

93. Ladics GS. Current codex guidelines for assessment of potential protein allergenicity. Food Chem Toxicol. Elsevier Ltd; 2008;46 Suppl 1:20-3. http://www.ncbi.nlm.nih. gov/pubmed/18708115.
94. Van Landschoot A. Gluten-free barley malt beers. Cerevisia. Elsevier B.V.; 2011;36:93-7. http://linkinghub. elsevier.com/retrieve/pii/S137371631100117X.

95. Foster AP, Knowles TG, Moore AH, Cousins PDG, Day MJ, Hall EJ. Serum IgE and IgG responses to food antigens in normal and atopic dogs, and dogs with gastrointestinal disease. Vet Immunol Immunopathol. 2003;92:113-24. http://linkinghub.elsevier.com/retrieve/pii/S01652427030 00333.

96. Shahar E, Kriboy N, Pollack S. White cell enhancement in the treatment of severe candidosis. Lancet. 1995;346: 974-5.

97. Murray MT, Pizzorno J. The Encyclopedia of healing foods. New York, NY: Atria Books; 2005. p. 912.

98. Almeida L de FD, Cavalcanti YW, Viana WP, Lima E de O. Screening da Atividade Antifúngica de Óleos Essenciais sobre Candida albicans. Rev Bras Ciências Saude. 2011;14:51-6.

99. Jantar I bin, Yassin MSM, Chin CB, Chen LL, Sim NL. Antifungal activity of the essential oils of nine Zingiberaceae species. Pharm Biol. 2003;41:392-7.

100. Joe MM, Jayachitra J, Vijayapriya M. Antimicrobial activity of some common spices against certain human pathogens. J Med Plants Res. 2009;3:1134-6.

101. Taguchi Y, Takizawa T, Ishibashi H, Sagawa T, Arai R, Inoue $\mathrm{S}$, et al. Therapeutic effects on murine oral candidiasis by oral administration of cassia (Cinnamomum cassia) preparation. Nihon Ishinkin Gakkai Zasshi. 2010;51:13-21. http://www.ncbi.nlm.nih.gov/pubmed/20185867.

102. Höferl M, Buchbauer G, Jirovetz L, Schmidt E, Stoyanova A, Denkova Z, et al. Correlation of antimicrobial activities of various essential oils and their main aromatic volatile constituents. J Essent Oil Res. 2009;21:459-64.

103. Roby MHH, Sarhan MA, Selim KA-H, Khalel KI. Antioxidant and antimicrobial activities of essential oil and extracts of fennel (Foeniculum vulgare L.) and chamomile (Matricaria chamomilla L.). Ind Crops Prod. Elsevier B.V.; 2013;44:437-45. http://linkinghub.elsevier.com/ retrieve/pii/S092666901200564X.

104. Bail S, Buchbauer G, Jirovetz L, Denkova Z, Slavchev A, Stoyanova A, et al. Antimicrobial activities of roman chamomile oil from France and its main compounds. J Essent Oil Res. 2009;21:283-7.

105. Ertürk Ö. Antibacterial and antifungal activity of ethanolic extracts from eleven spice plants. Biologia (Bratisl). 2006; 61:275-8. http://www.springerlink.com/index/10.2478/ s11756-006-0050-8.

106. Bozin B, Mimica-Dukic N, Samojlik I, Jovin E. Antimicrobial and antioxidant properties of rosemary and sage (Rosmarinus officinalis L. and Salvia officinalis L., Lamiaceae) essential oils. J Agric Food Chem. 2007; 55:7879-85. http://www.ncbi.nlm.nih.gov/pubmed/177 08648 .

107. Carretto C de FP, Navas EAF de A, Paradella TC, Oliveira LD de, Junqueira JC, Jorge AOC. Efeitos do chá de tomilho sobre a aderência in vitro de Streptococcus mutans ao esmalte dentário e Candida albicans à resina acrílica. Rev Oncol UNESP. 2007;36:281-6.

108. Abdul BA, Hassan AM, Hassan AS. In vitro antimicrobial activity of Thymus vulgaris, Origanum vulgare and 
Rosmarinus officinalis against dental caries pathogens. Haitham J Pure Appl Sci. 2012;25:1-7.

109. Van Vuuren SF, Suliman S, Viljoen AM. The antimicrobial activity of four commercial essential oils in combination with conventional antimicrobials. Lett Appl Microbiol. 2009;48:440-6. http://www.ncbi.nlm.nih.gov/ pubmed/19187494.

110. Murray MT. The healing power of herbs. 2nd ed. Gramercy Books, editor. New York, NY: Random House; 2004.
111. Vanaclocha B, Cañigueral S. Fitoterapia: Vademecum de Prescripción. 4th ed. Masson, editor. Barcelona; 2003.

112. Amara AA, Shibl A. Role of Probiotics in health improvement, infection control and disease treatment and management. Saudi Pharm J. King Saud University; 2013;1-8. http://linkinghub.elsevier.com/retrieve/pii/S13 19016413000819.

113. Kaur IP, Kuhad A, Garg A, Chopra K. Probiotics: delineation of prophylactic and therapeutic benefits. J Med Food. 2009; 12:219-35. http://www.ncbi.nlm.nih.gov/pubmed/19459724. 